\title{
Effects of Tubal Sterilization on Women's Sexuality and Risk Factors Causing Sexual Dysfunction
}

\author{
Ahmet Yıldı' ', Serkan Kumbasar', Süleyman Salman², Aytek Şık \\ ${ }^{1}$ Clinic of Gynaecology, Sakarya Training and Research Hospital, Sakarya, Turkey \\ ${ }^{2}$ Clinic of Gynaecology, Gaziosmanpaşa Training and Research Hospital, İstanbul, Turkey \\ ${ }^{3}$ Department of Gynaecology, İstanbul Aydın University, İstanbul, Turkey
}

\begin{abstract}
Objective: The aim of this study was to evaluate the incidence of sexual dysfunction and associated risk factors in women who had undergone tubal sterilization and those who had not undergone tubal sterilization.

Methods: In this case-controlled sectional study, 100 women who underwent tubal sterilization were included as the case group and 100 women who were healthy, reproductive, and sexually active were included as the control group. A detailed medical and sexual history was taken from all the patients, and they were evaluated by filling the Female Sexual Function Index (FSFI) form in order to determine the status of sexual function. In 200 cases, the relationship of age, marital status, income level, number of births, alcohol use, cigarette smoking, and BMI with the FSFI scores was investigated by regression analysis.

Results: While the rate of sexual dysfunction was $82 \%$ in the tubal sterilization group, it was found to be $32 \%$ in the control group ( $p<0.001$ ). In the tubal sterilization group, desire, arousal, lubrication, orgasm, satisfaction, and pain scores were reported to be significantly lower than those in the control group $(p<0.001)$. According to logistic regression analysis, in women whose monthly income was $<\$ 500$ (OR 4.331 ); whose marital status was single, widowed, or divorced (OR 13.769); whose parity was >2 (OR 3.462); and who had undergone BTL (OR 7.876) were found to have an increased risk of sexual dysfunction.
\end{abstract}

Conclusion: The termination of fertility, which is one of the most significant abilities of women, by tubal sterilization seems to be an important factor for sexual dysfunction, especially in the presence of risk factors.

Keywords: Tubal sterilization, sexual dysfunction, women sexuality

\section{INTRODUCTION}

It is stated that many psychosocial and cultural factors play a role in the development of sexual dysfunction in women. When these factors are evaluated, it is observed that sexuality is a multidimensional and multidisciplinary process that is derived from psychosocial, cultural, behavioral, and organic reasons and that sexual function disorders develop within this versatile network of relationships (1). It is estimated that physiological, hormonal, structural, and psychological changes caused by surgical interventions related to reproductive organs may lead to several sexual problems among women (2). Previous studies have shown that many surgical interventions, particularly hysterectomy, negatively affect the body image, self-respect, femininity characteristics, and sexual functions of women (3). The tubal sterilization operation is the most commonly used permanent contraception method worldwide (4). The incidence of tubal sterilization in Turkey was determined to be $5.7 \%$ based on a previous study (5). In the performed studies, it has been reported, albeit with different results, that many problems such as post-tubal ligation syndrome, menstrual dysfunction, pelvic pain, and sexual dysfunction have been experienced by patients following tubal sterilization (6).
In this study, we aimed to investigate the effect of tubal sterilization on female sexuality and the risk factors leading to sexual dysfunction among women aged between 26 and 40 years who were admitted to our gynecology outpatient clinic.

\section{METHODS}

This case control study was performed at the Istanbul Şişli Education and Research Hospital Obstetrics and Gynecology Department between May 2012 and October 2012. The study was started after obtaining Şişli Ethics Committee approval and written consents from all the included patients. In total, 100 women who were sexually active, who were at a reproductive age and were aged between 26 and 40 years, and who had undergone tubal sterilization surgery at least one year ago were enrolled in the study as the tubal sterilization group. The sociodemographic characteristics of the women in this group and their previous surgical histories were recorded. Detailed physical examinations were performed, and women who had gynecological diseases, who had a chronic disease history, whose BMI was above $40 \mathrm{~kg} / \mathrm{m}^{2}$, who did not have an active sexual life, who did not have a sexual activity within the last one month, who were in the postmenopausal period, who were using oral 
contraceptives and antidepressant drugs, who had a history of sexual abuse, who had undergone a surgical operation (except for cesarean or tubal sterilization), and who were pregnant were excluded from the study.

In our study, the laparatomic partial salpingectomy (Pomeroy) method and laparascopic bipolar electrocoagulation method were used as the tubal sterilization methods. In total, 100 healthy women who were again within the same age group, who were sexually active, who were at a reproductive age, and who were admitted to the gynecology outpatient clinic of our hospital were enrolled in the study as the control group.

Sexual function inquiry was done by filling the FSFI form, which included 19 questions. This form was developed by Rosen et al. (7), and its validation was performed after translation into Turkish. This test can be performed for women who have had sexual intercourse within the last one month and is graded between 2 and 36 points. While sexual desire, arousal, lubrication, orgasmic function, overall satisfaction, and sexual pain parameters are evaluated under subheadings, the scores obtained are multiplied by their own coefficients and a total score is obtained. The diagnosis of sexual dysfunction is made when the total score of FSFI is below 26.55 (7). The status of sexual function was evaluated in our study by taking this cut-off value into consideration.

\section{Statistical Analysis}

For descriptive statistics, numbers and percentages were used for categorical variables and mean \pm standard deviation (SD) values were used for numerical variables. Student t-test was used to compare the numerical variables in case and control groups, while the ANOVA test was used to compare the numerical variables in multiple groups. Data were analyzed by the Statistical Package for the Social Sciences 15.0 program (SPSS Inc.; Chicago, IL, USA), and $\mathrm{p}<0.05$ was considered as statistically significant. The multiple logistic regression analysis (Method=Enter) method was used for the detection of risk factors that may cause sexual dysfunction. Here, $p<0.05$ was considered significant.

\section{RESULTS}

One hundred women were included in the tubal sterilization group and 100 women were included in the control group in the study. The mean age of the patients in the tubal sterilization group was $37.05 \pm 4.75$ years, the mean number of children was $3.64 \pm 1.0$, and the mean body mass index was $27.8 \pm 3.7 \mathrm{~kg} / \mathrm{m}^{2}$. These mean values were $35.66 \pm 4.25,3.3 \pm 1.2$, and $25.2 \pm 3.7$ in the control group, respectively. There was no statistically significant difference between both groups in terms of these parameters (Table 1).

The demographic data of the women included in the study were evaluated and compared, and no statistically significant difference was found between the groups in terms of age, number of children, body mass index, marital status, education level, employment status, smoking status, and alcohol habit. For the type of operation, $74 \%$ of the patients $(n=74)$ were operated by laparotomy (Pomeroy method) and 26\% $(n=26)$ were operated by the laparascopic bipolar coagulation method. While $72 \%$ of the patients reported the reason for tubal sterilization as already having a sufficient number of children, 18\% preferred tubal sterilization for the desire of exact contraception, $4 \%$ for economic and social reasons, $4 \%$ for the inability to use an intrauterine device, and $2 \%$ for a poor obstetric history (Table 2).

While $22 \%$ of the patients in the tubal sterilization group complained about dismenorrhea at the postoperative evaluation, $10 \%$ of the cases had regrets. The reasons for regret were observed to be gynecological or menstrual problems in 60\%, loss of sexuality in $20 \%$, and divorce/remarriage in $20 \%$ (Table 3 ).

While the rate of sexual dysfunction was detected as $82 \%$ in the tubal sterilization group, it was determined to be $32 \%$ in the group that did not undergo tubal sterilization. The difference was statistically significant $(p<0.001)$. While the mean total FSFI score was $20.99 \pm 6.7$ in the tubal sterilization group, it was found to be $26.916 \pm 5.3$ in the control group. In addition, in the evaluation of the FSFI subgroup scores, it was determined that the scores of desire, arousal, lubrication, orgasm, satisfaction, and pain were significantly lower in the tubal sterilization group compared to in the control group $(p<0.001)$ (Table 4).

When the risk factors of the 200 cases in the study were evaluated for sexual dysfunction, it was found that age, smoking status, alcohol use, BMI, education level (elementary school), and employment status (housewife) did not generate a risk in terms of sexual dysfunction ( $p>0.05$ ) (Table 4). In the logistic regression analysis, it was observed that there was a risk for sexual dysfunction in women whose income level was low, who had more than two children, who underwent BTL, and whose marital status was divorced or single. In the logistic regression analysis, it was observed that there was a risk of sexual dysfunction in women whose income level was low, who had more than two children, who underwent $B T L$, and whose marital status was divorced or single. This risk was 4.3-fold more in women whose income level was below $\$ 500$ compared to the ones whose income level was above $\$ 500$, 3-fold more in women who had more than two children compared to the ones who had less than two children, 7-fold more in the ones who underwent BTL compared to the ones who did not, and 12-fold more in singles compared to the married women, and these differences were statistically significant. The results of the logistic regression analysis generated by some variables that are possibly associated with sexual dysfunction (age, education level, employment status, marital status, income status of the family, number of deliveries, smoking status, alcohol use, BMI) are given in Table 5.

\section{DISCUSSION}

Female sexual dysfunction is a term used for describing many sexual problems, such as decreased sexual desire, interest and arousal, orgasm difficulties, and dyspareunia. Female sexual dysfunction is an age-dependent multifactorial problem that affects $30-50 \%$ of women and negatively affects their quality of life (8). 
Table 1. Comparison of the groups in terms of age, number of children, and body mass index

\begin{tabular}{|c|c|c|c|}
\hline & $\begin{array}{l}\text { Tubal sterilization } \\
\qquad(n=100) \\
\text { mean } \pm S D\end{array}$ & $\begin{array}{c}\text { Control } \\
(n=100) \\
\text { Mean士SD }\end{array}$ & $p$ \\
\hline Age (years) & $37.05 \pm 4.75$ & $35.66 \pm 4.25$ & $>0.05$ \\
\hline Children (number \pm SD) & $3.64 \pm 1.0$ & $3.3 \pm 1.2$ & $>0.05$ \\
\hline $\mathrm{BMI}\left(\mathrm{kg} / \mathrm{m}^{2}\right)$ & $27.8 \pm 3.7$ & $25.2 \pm 3.7$ & $>0.05$ \\
\hline $\begin{array}{l}\text { Marriage status } \\
\text { (married) }\end{array}$ & 98 & 92 & $>0.05$ \\
\hline $\begin{array}{l}\text { Educational level } \\
\text { (elementary school) }\end{array}$ & 74 & 70 & $>0.05$ \\
\hline Job status (housewife) & 76 & 74 & $>0.05$ \\
\hline Smoking habit & 52 & 48 & $>0.05$ \\
\hline Alcohol use & 8 & 10 & $>0.05$ \\
\hline Income level $<\$ 500$ & 61 & 56 & $>0.05$ \\
\hline Income level $>\$ 500$ & 39 & 44 & $>0.05$ \\
\hline
\end{tabular}

Table 2. Reasons for sterilization

\begin{tabular}{|l|c|c|}
\hline & $\mathbf{n}$ & $\%$ \\
\hline Having sufficient number of children & 72 & 72 \\
\hline Desire for exact contraception & 18 & 18 \\
\hline Economic reasons & 4 & 4 \\
\hline Poor obstetric history & 2 & 2 \\
\hline Inability to use intrauterine device & 4 & 4 \\
\hline
\end{tabular}

\section{Table 3. Reasons for regret}

\begin{tabular}{|c|c|c|}
\hline & n & $\%$ \\
\hline $\begin{array}{l}\text { Repeated gynecological and } \\
\text { menstrual problems }\end{array}$ & 6 & 60 \\
\hline Loss of sexuality & 2 & 20 \\
\hline Divorce/remarriage & 2 & 20 \\
\hline Wish for more children & 0 & 0 \\
\hline
\end{tabular}

The ratios of sexual dysfunction vary between countries. The study including the largest series on this subject was performed in the United States by Shifren et al. (9), who found the incidence of sexual dysfunction to be $43.1 \%$ in 31581 women at the age of 18 years and above. In the study by Cayan et al. (10) on 179 women, the rate of sexual dysfunction was detected as $46.9 \%$. In the same study, no significant effects of smoking, duration of marriage, previous pelvic operations, and contraception meth-
Table 4. Comparison of FSFI scores of the groups

\begin{tabular}{|l|c|c|c|}
\hline & $\begin{array}{c}\text { Tubal sterilization } \\
(\mathbf{n = 1 0 0 )} \\
\mathbf{m e a n} \pm \text { SD }\end{array}$ & $\begin{array}{c}\text { Control } \\
(\mathbf{n = 1 0 0 )} \\
\mathbf{m e a n} \pm \text { SD }\end{array}$ & $\mathbf{p}$ \\
\hline Desire & $3.066 \pm 0.98904$ & $3.804 \pm 0.77248$ & $<0.001$ \\
\hline Arousal & $3.22 \pm 1.0174$ & $4.33 \pm 0.85147$ & $<0.001$ \\
\hline Lubrication & $3.612 \pm 1.16262$ & $4.658 \pm 0.93962$ & $<0.001$ \\
\hline Orgasm & $3.644 \pm 1.18031$ & $4.622 \pm 0.91189$ & $<0.001$ \\
\hline Satisfaction & $3.628 \pm 1.15353$ & $4.914 \pm 0.91563$ & $<0.001$ \\
\hline Pain & $3.82 \pm 1.23520$ & $4.5880 \pm 1.15027$ & $<0.001$ \\
\hline Total FSFI & $20.991 \pm 6.7718$ & $26.916 \pm 5.3357$ & $<0.001$ \\
\hline FSFI: Female Sexual Function Index; TS: tubal sterilization; & \\
\hline SD: standard deviation & &
\end{tabular}

Table 5. Risk factor analysis for sexual dysfunction

\begin{tabular}{|c|c|c|c|c|}
\hline \multirow{2}{*}{$\begin{array}{l}\text { Independent } \\
\text { variables }\end{array}$} & \multirow[b]{2}{*}{$p$} & \multirow{2}{*}{$\begin{array}{l}\text { Odds } \\
\text { ratio }\end{array}$} & \multicolumn{2}{|c|}{$\begin{array}{l}95 \% \text { C.I. for } \\
\text { odds ratio }\end{array}$} \\
\hline & & & Lower & Upper \\
\hline Age & 0.077 & 0.898 & 0.796 & 1.012 \\
\hline $\begin{array}{l}\text { Marital status } \\
\text { (Single) }\end{array}$ & 0.006 & 13.769 & 2.145 & 88.390 \\
\hline $\mathrm{BMI}(>25.5)$ & 0.19 & 0.524 & 0.233 & 1.180 \\
\hline $\begin{array}{l}\text { Employment } \\
\text { (Housewife) }\end{array}$ & 0.671 & 1.240 & 0.458 & 3.356 \\
\hline $\begin{array}{l}\text { Income } \\
(<1500 \mathrm{TL})\end{array}$ & 0.018 & 4.359 & 1.284 & 14.796 \\
\hline Smoking (Yes) & 0.947 & 0.968 & 0.375 & 2.502 \\
\hline Alcohol (Yes) & 0.67 & 1.135 & 0.259 & 4.980 \\
\hline Parity $(>2)$ & 0.005 & 3.462 & 1.453 & 8.251 \\
\hline BTL (Yes) & 0.001 & 7.876 & 3.048 & 20.351 \\
\hline Education & 0.541 & 0.501 & 0.147 & 1.703 \\
\hline Constant & 0.273 & 11.008 & & \\
\hline $\begin{array}{l}\text { Dependent } \\
\text { variable: } \\
\text { FSF }\end{array}$ & $\begin{array}{c}\text { Predicted } \\
\text { FSF } \\
\text { (Yes)= } \\
85.6\end{array}$ & $\begin{array}{c}\text { Predicted } \\
\text { FSF } \\
\text { (No)= } \\
68.0\end{array}$ & $\begin{array}{l}\text { Predicted: } \\
79.0\end{array}$ & \\
\hline \multicolumn{5}{|c|}{$\begin{array}{l}\text { Multiple Logistic Regression (Method=Enter) C.I : Confidence interval. } \\
\text { Cut-off values for BMI and parity based on FSFI were calculated by ROC } \\
\text { curve analysis. The cut-off values used are optimal cut-offs. }\end{array}$} \\
\hline
\end{tabular}

ods were found on sexual dysfunction, but it was determined that factors such as advanced age, low education level, unemployment, chronic disease history, previous pregnancies, and menopause negatively affected the sexual functions in women (10). In our study, the sexual functions of 200 women were questioned and the total ratio of sexual dysfunction was found to 
be $57 \%$. Again in our study, the ratio of sexual dysfunction was found to be $82 \%$, whereas it was $32 \%$ in the control group.

Tubal sterilization has now become the most common method used for family planning in the world. The most commonly known change among the biological changes that occur following tubal sterilization is poststerilization syndrome, which includes hormonal changes and menstrual abnormalities (11). Hormonal changes, the use of oral contraceptives before sterilization, and decreased ovarian blood flow by the dissection of the ovarian branches of the uterine artery during sterilization are considered responsible for the etiology of this syndrome (12).

There are only a limited number of articles investigating the effects of tubal sterilization on sexual function. In these studies, some have reported similar sexual scores between patients who did and did not undergo tubal sterilization, while some have reported that tubal sterilization had positive effects (13), such as a decrease in the anxiety of getting pregnant. This effect is shown to be the only reason for the common availability of tubal sterilization worldwide.

In our study, 100 patients who were admitted to the gynecology outpatient clinic of our hospital and who underwent tubal sterilization and 100 healthy women who had similar demographic characteristics were included, and the FSFI scores of both groups were compared. The total scores of the female sexual dysfunction index in the tubal sterilization group were found to be lower than in the control group, and at a statistically significant level. Besides the total scores, all of the female sexual dysfunction index subgroup scores, including desire, arousal, lubrication, orgasm, satisfaction, and pain, were statistically significantly lower. In parallel to our study, 90 patients who underwent tubal sterilization and 100 healthy premenopausal women with similar demographic characteristics were compared for sexual dysfunction in the study by Gulum et al. (14), and both groups were applied the female sexual dysfunction index questionnaire. As a result of this study, the total FSFI score and subgroup scores were found to be significantly lower in the tubal sterilization group. Again similarly, Smith et al. (15) performed a study on 3448 Australian women aged between 16 and 64 years old and found that desire, orgasm, satisfaction, and pain scores in their tubal sterilization group were significantly lower compared to in their control group.

When the risk factors of the 200 patients in the present study were examined for sexual dysfunction, it was found that age, smoking status, alcohol use, BMI, education level (elementary school), and employment status (housewife) were not risk factors in terms of sexual dysfunction ( $p>0.05)$. The risk of experiencing sexual problems was observed in women whose income level was low, who had more than two children, who underwent BTL, and who were divorced or single (marital status) ( $p>0.05)$.

In our study, the mean age of the tubal sterilization group was $37.05 \pm 4.75$ years old (26-40), while for the control group the mean age was $35.66 \pm 4.25$ (26-40) years old; and there was no statistically significant difference in the mean ages. In the study by Lindau et al. (16), sexual function was evaluated in 3005 men and women between the ages of 57 and 85 years old, and they determined that the age-dependent decrease in sexual function was more significant in women compared to men. In the study by Laumann et al. (17), it was found that sexual function decreased by age. In our study, the age factor did not show a negative effect on sexual function. Considering that menopause has negative effects on sexual functions, the majority of our study group were premenopausal women and this explains why the age factor was not a negative factor in our study (18). This result suggests that age alone is not the main factor affecting sexual functions; rather, it is the menopause that occurs with advanced age.

In the literature, it is emphasized that sexual dysfunction occurs less commonly in married women compared to single, widow, or divorced women $(17,18)$. In accordance with the literature, the ratio of sexual dysfunction in unmarried women was found to be significantly higher compared to married women.

A correlation was detected between economic status and sexual dysfunction in the study by Echeverry et al. (19). In addition, there are some studies showing that income status does not affect sexual life. In the study by Elnashar et al. (20), no correlation was found between income and sexual dysfunction. In our study, it was detected that income status might generate a 3.4-fold more risk of sexual dysfunction based on the logistic regression analysis $(p<0.05)$. In an environment where individuals cannot meet their fundamental needs, such as eating, drinking, and housing, it may be concluded that it is difficult to search for the solution of sexual problems.

There are some reports presenting multiparity as an important risk factor for sexual dysfunction (21). In our study, parity was detected to be a risk factor in terms of sexual dysfunction, and it was found that women who had three and more deliveries had a 3.4-fold higher risk ratio of sexual dysfunction. On the contrary, there are some reports presenting opposite results. In the study by Guvel et al. (22) in Turkey, no correlation was found between multiparity and the incidence of female sexual dysfunction.

There was a statistically significant difference between the tubal sterilization group and the control group in terms of smoking status among the women in our study. There are controversial results in the studies investigating the effect of smoking on sexual desire disorders. In the study by Oksuz et al. (23) on 518 women, smoking was found to be a risk factor for female sexual dysfunction. However, in the study by Cayan et al. (10) investigating the risk factors for female sexual dysfunction, smoking was not determined to be a risk factor; also, smoking was not found to be a risk factor in our study.

In our study, it was observed that the education level did not have an effect on sexual functions. This situation does not comply with the studies with larger series on this subject. In the study by Kadri et al. (24), it was observed that sexual dysfunction was more common especially among women whose education level was below high school. In our country, the 
study by Aslan (25) reported that FSD was more commonly seen among women whose education level was low. However; Guvel et al. (22) could not find any relationship between education level and FSD incidence. In the studies by Gulum et al. (14) on 190 women and by Fahami et al. (26) on 174 women, it was detected that the ratio of sexual dysfunction decreased as the education level of the women and couples increased. In contrast, Addis et al. (27) determined that the ratio of sexual dysfunction increased as the education level increased. In Addis's study (27), this situation was explained by the fact that an increase in education level brings a higher probability to encounter more sources of stress in social life. In our study, the education level was not determined to be a risk factor for female sexual dysfunction.

In the study by Ponholzer et al. (28), it was stated that alcohol use was a risk factor for sexual dysfunction; while in the study by Ostbye et al. (29), obesity was shown to be a risk factor for sexual dysfunction. In our study, these risk factors did not show a negative effect on sexual functions.

In our study, patients who underwent tubal sterilization were asked if they had regrets following sterilization and this ratio was found to be $10 \%$. In the study by Hillis et al. (30), this ratio was found to be $20 \%$, while the wish for having more children was shown to be the reason of regret for $33 \%$ of women. In our study, gynecological or menstrual problems were shown to be the reasons of regret for $60 \%$ of the women, and loss of sexuality was determined to be in second place.

\section{CONCLUSION}

Sexual dysfunction in women is a common condition that affects their quality of life. In this study, we found that the FSFI scores in women who had underwent tubal sterilization operation were significantly lower compared to women who had not undergone any operation. It was also determined that the termination of fertility in women with tubal sterilization was a significant reason for female sexual dysfunction in the presence of risk factors such as income level, increased number of children, marital status, and the implementation of BTL. This situation increases the significance of a detailed consultation before tubal sterilization, especially in the presence of risk factors. Results from studies with larger patient populations are required to provide more effective analysis.

Ethics Committee Approval: Ethics committee approval was received for this study from the ethics committee of Şişli Training and Research Hospital.

Informed Consent: Written informed consent was obtained from patients who participated in this study.

Peer-review: Externally peer-reviewed.

Author Contributions: Concept - S.K.; Design - A.Y.; Supervision A.Y.; Resources - S.S., A.Ş.; Materials - S.S.; Data Collection and/or Processing - A.Y.; Analysis and/or Interpretation - A.Y., S.K., S.S., A.S..; Literature Search - A.Y.; Writing Manuscript - S.K.; Critical Review - A.Y., S.K., S.S., A.Ş.; Other - A.Y.
Conflict of Interest: No conflict of interest was declared by the authors.

Financial Disclosure: The authors declared that this study has received no financial support.

\section{REFERENCES}

1. Berman J. Etiology and management of female sexual dysfunction. Urology Times, ABI/ INFORM Trade \& Industry 2004; 3.

2. Qureshi S, Ara Z, Qureshi VF, Al-Rejaie SS, Aleisa AM, Bakheet SA, et al. Sexual Dysfunction in Women: An Overview of Psychological/ Psycho-social, Pathophysiological, Etiological Aspects and Treatment Strategies. Pharmacogn Rev 2007; 1: 41-8.

3. Kuşçu NK, Oruç S, Ceylan E, Eskicioğlu F, Göker A, Çağlar H. Sexual life following total abdominal hysterectomy. Arch Gynecol Obstet 2005; 271: 218-21. [CrossRef]

4. Kulier R, Boulvain M, Walker DM, De Candolle G, Campana A. Minilaparotomy and endoscopic techniques for tubal sterilisation. Cochrane Database Syst Rev 2004; 3: 37. [CrossRef]

5. Tanriverdi HA, Akbulut OV. Laparoscopic and hysteroscopic tubal sterilization. J Surg Med Sci 2006; 2: 30-7.

6. Gentile G, Kaufman S, Helbig D. Is there any evidence for a posttubal ligation syndrome? Fertil Steril 1998; 69: 179-89. [CrossRef]

7. Rosen R, Brown C, Heiman J, Leiblum S, Meston C, Shabsigh R, et al. The female sexual function index (FSFI): a multidimensional self report intsrument for the assesment of female sexual function. $J$ Sex Marital Ther 2000; 26: 191-208. [CrossRef]

8. Berman JR, Goldstein I. Female sexual dysfunction. Urol Clin North Am 2001; 28: 404-16. [CrossRef]

9. Shifren JL, Monz BU, Russo PA, Segreti A, Johannes CB. Sexual problems and distress in United States women. Obstet Gynecol 2008; 112: 970-8. [CrossRef]

10. Çayan S, Akbay E, Bozlu M, Canpolat B, Acar D, Ulusoy E. The prevalance of female dysfunction and potential risk factors that may impair sexual function in Turkish women. Urol Int 2004; 72: 52-7. [CrossRef]

11. Williams EL, Jones HE, Merrill RE. The subsequent course of patients sterilized by tubal ligation: a consideration of hysterectomy for sterilization. Am J Obstet Gynecol 1951; 61: 423-6. [CrossRef]

12. Rock JA, Jones HW. Te Linde's Operative Gynecology. Lippincott Williams \& Wilkins, 9th edn, chapter 23, 2005. pp 609-29.

13. Costello C, Hillis SD, Marchbanks PA, Jamieson DJ, Peterson HB. The effect of interval tubal sterilization on sexual interest and pleasure. Obstet Gynecol 2002; 100: 511-7. [CrossRef]

14. Gulum M, Yeni E, Şahin MA, Savas M, Ciftci H. Sexual functions and quality of life women with tubal sterilization. Int J Impot Res 2010; 22: 267-71. [CrossRef]

15. Smith A, Lyons A, Ferris J, Richters J, Pitts M, Shelley J. Are sexual problems more common in women who had tubal ligation? A population-based study of Australian women. BJOG 2010; 117: 463-8. [CrossRef]

16. Lindau TS, Schumm LP, Lauman EO, Levinson W, O'Muircheartaigh CA, Waite LJ. A study of sexuality and health among older adults in the United states. N Engl J Med 2007; 357: 762-4. [CrossRef]

17. Laumann EO, Paik A, Rosen RC. Sexual dys-function in the United States: Prevalence and pre-dictors. JAMA 1999; 281: 537-44. [CrossRef]

18. Dennerstein L, Lehert $P$, Burger $H$, Dudley E. Factors affecting sexual functioning of women in the mid-life years. Climacteric 1999; 2: 254-62. [CrossRef]

19. Echeverry MC, Arango A, Castro B, Raigosa G. Study of the prevalence of female sexual dysfunction in sexually active women 18 to 
40 years of age in Medellín, Colombia. J Sex Med 2010; 7: 2663-9. [CrossRef]

20. Elnashar AM, El-Dien Ibrahim M, El-Desoky MM, Ali OM, El-Sayd Mohamed Hassan M. Female sexual dysfunction in lower Egyp. BJOG 2007; 114: 201-6. [CrossRef]

21. Safarinejad MR. Female sexual dysfunction in a population-based study in Iran: prevalence and associated risk factors. Int J Impot Res 2006; 18: 382-95. [CrossRef]

22. Güvel S, Yaycıoğlu Ö, Bağış T, Savaş N, Bulgan E, Özkardeş H. Evli kadınlarda cinsel fonksiyonlara etkin faktörler. Turk J Urol 2003; 29: 43-8.

23. Öksüz E, Malhan S. Prevalence and risk factors for female sexual dysfunction in Turkish women. J Urol 2006; 175: 654-8. [CrossRef]

24. Kadri N, McHichi Alami KH, McHakra T. Sexual dysfunction in women: population based epidemiological study. Arch Women Mental Health 2002; 5: 59-63. [CrossRef]

25. Aslan E, Beji NK, Gungor I, Kadioglu A, Dikencik BK. Prevalence and risk factors for low sexual function in women: a study of 1,009 women in an outpatient clinic of a university hospital in Istanbul. J Sex Med 2008; 5: 2044-52. [CrossRef]

26. Fahami F, Beygi M, Zahraei RH, Arman S. Sexual dysfunction in menopausal women and the socioeconomic state. IJNMR 2007; 61: 4 .

27. Addis IB, Van Den Eeden SK, Wassel-Fyr CL, Vittinghoff E, Brown JS, Thom DH. Reproductive risk factors for incontinence study and Kaiser Study Group Sexual activity and function in middle aged and older women. Obstet Gynecol 2006; 107: 755-64. [CrossRef]

28. Ponholzer A, Roehlich M, Racz U, Temml C, Madersbacher S. Female Sexual Dysfunction in a Healthy Austrian Cohort: Prevalence and Risk Factors. Eur Urol 2005; 47: 366-75. [CrossRef]

29. Ostbye T, Kolotkin RL, He H, Overcash F, Brouwer R, Binks M, et al. Sexual functioning in obese adults enrolling in a weight loss study. J Sex Marital Ther 2011; 37: 224-35. [CrossRef]

30. Hillis SD, Marchbanks PA, Tylor LR, Peterson HB. Poststerilization Regret: Findings From the United States Collaborative Review of Sterilization. Obstet Gynecol 1999; 93: 889-95. [CrossRef] 